\title{
Revealing the social face of innovation
}

\section{AUTHORS:}

Tim G.B. Hart ${ }^{1,2}$

Kgabo H. Ramoroka ${ }^{3}$

Peter T. Jacobs ${ }^{3}$

Brigid A. Letty ${ }^{4}$

\section{AFFILIATIONS:}

${ }^{1}$ Economic Performance and

Development, Human Sciences

Research Council, Pretoria,

South Africa

2Department of Sociology and Social Anthropology, Stellenbosch University,

Stellenbosch, South Africa

${ }^{3}$ Economic Performance and Development, Human Sciences Research Council, Cape Town, South Africa

${ }^{4}$ Institute for Natural Resources, Pietermaritzburg, South Africa

\section{CORRESPONDENCE TO:} Tim Hart

\section{EMAIL:}

thart@hsrc.ac.za

\section{POSTAL ADDRESS:}

Economic Performance and Development, Human Sciences Research Council, Private Bag X41, Pretoria 0001, South Africa

\section{DATES:}

Received: 11 Apr. 2014

Revised: 31 Oct. 2014

Accepted: 16 Jan. 2015

\section{KEYWORDS:}

social innovation; inclusive development; rural municipalities; actor-oriented approach

\section{HOW TO CITE:}

Hart TGB, Ramoroka KH, Jacobs PT, Letty BA. Revealing the social face of innovation. S Afr J Sci. 2015;111(9/10), Art. \#2014-0126, 6 pages. http://dx.doi.org/10.17159/ sajs.2015/20140126
(C) 2015. The Author(s). Published under a Creative Commons Attribution Licence.
Despite the introduction of social innovation in the 1996 White Paper on Science and Technology, the concept of social innovation has not been actively implemented or even diffused outside of the policy arena in South Africa. Perceptions about what the concept of social innovation should encompass are contested and range from ideas of social welfare outcomes, public goods and a primary focus on the poor. More recently, the emphasis has been on inclusive development that embraces and supports the poor as innovators and which incorporates elements of social and economic development. While contestation in terminology persists, evidence from South Africa's rural areas suggests that although there may be limited state intervention, hampered by structural constraints, and limited understanding of contemporary ideas about innovation and social innovation, local actors practise a variety of forms of social innovation. In most instances, the purpose is to improve social and economic well-being of the poor. Such innovation activities occur almost as widely and as often as strictly commercially oriented innovation activities. However, it is unclear from observed social innovation practices who should benefit from these practices (the poor or everyone), how (directly or indirectly) and when (immediately or gradually). It is suggested that extensive use of the actor-oriented sociological approach to understanding social dynamics in both science and development can provide a means of understanding the subtleties involved in innovation practices and its use should be adopted to address structural challenges within the National System of Innovation that mediate against the contribution of innovations to the poor for inclusive development.

\section{Introduction}

Two years after South Africa's first democratic elections, the National Department of Arts, Culture, Science and Technology introduced the 1996 White Paper on Science and Technology ${ }^{1}$ - a necessary and progressive document that aimed to change the thinking about innovation in South Africa and restructure the country's National System of Innovation (NSI). The White Paper was guided by the experiences of innovation systems in other countries, particularly those in North America and Western Europe, and in emerging economies in Asia and Latin America. It emphasised the changes required to shift South Africa's relatively dysfunctional NSI away from its historical focus on labour-intensive commodity production and the military-industrial complex of the latter apartheid years. Unfortunately, policy implementation and related strategies have struggled:

- to effectively change the structure of the NSI

- to make the NSI more representative of key innovation actors by accommodating the marginalised, the private sector and civil society

- to broaden the understanding around innovation activities and reduce the bias of the traditional focus on technical- and business-oriented outputs

- to expand the ideas about and practices related to social innovation as a means of making the outputs of innovation more relevant to society to encourage inclusive development.

While many of the structural constraints of the system undoubtedly remain, the notion of social innovation is probably the least examined area, being largely overlooked beyond any 'trickle-down' social and economic benefits that arise from technical and business innovations. The 2012 Final Report of the Ministerial Review of South Africa's Science, Technology and Innovation Landscape ${ }^{2}$ also drew attention to the need to focus on the poor and ensure they benefit from NSI activities, but the report struggles to portray what the idea of social innovation should encompass, its purpose beyond notions of poverty reduction and how to ensure its place in the NSI so that it has far-reaching, direct and positive social outcomes for marginalised members of society.

Despite the trend in recent years to acknowledge the desirability for the use of innovations to improve society at large, as well as specific vulnerable groups within society, ${ }^{3,4}$ the meaning and use of social innovation is contested and numerous broad and narrow definitions exist. Their existence makes it challenging to implement such an idea effectively and efficiently into South Africa's science, technology and innovation (STI) landscape. In trying to address this challenge, we ask some pertinent questions and attempt to answer them pragmatically:

- Do we need a special category of innovation such as social innovation?

- Does social innovation require its own specific place in the NSI?

- Are current definitions and understandings of this term useful to policymaking and intervention?

- How could we improve our understanding of innovation generally, and social innovation particularly?

We start by briefly reviewing key innovation policy documents since 1996 to understand how social innovation is interpreted within South Africa's policy environment. To contextualise this understanding more broadly, our focus then shifts to the contemporary global understandings of innovation and social innovation in particular. Using evidence obtained from the Rural Innovation Assessment Toolbox (RIAT) pilot study conducted during 2012 and 2013, we show that understandings of innovation and social innovation are extremely blurred in South 
Africa's rural areas because STI policy ideas have not been effectively disseminated to innovators in these areas. Why does this situation arise? The absence of a clear understanding and reasons for differences in innovation perceptions and practices suggests that social innovation cannot be simply included into STI policies with the expectation that doing so will ensure broader societal benefits. Drawing on work from the sociology of science and rural development, we argue that in order to bring about change that will reduce structural obstacles within the NSI, particularly those that mediate against social and economic innovation for and by the poor and vulnerable sectors of society, one needs to explore the roles of actors throughout the innovation system and consider their perceptions and world views and what motivates them. These factors are fundamentally different. The most pragmatic way to do this is to adopt an actor-oriented sociology of innovation approach to understanding the social subtleties in the innovation process. Subtleties include what models are dominant and why; who gets what resources for innovation purposes; and what ideas and products are diffused and encouraged. Greater understanding of existing challenges will enable us to effectively address challenges and encourage the STI landscape to be more inclusive, not only in what it does, but in how it does it.

\section{Innovation policy and strategy in South Africa}

The 1996 White Paper recognised the importance of both formal government, higher education and research institutions, private sector and civil society and informal - households and individuals - actors in the NSI. ${ }^{1}$ Highlighting the experiences of developing economies in Asia and Latin America, the 1996 White Paper acknowledged that an exclusive focus on technical- and business-oriented innovation was insufficient and that social innovation should be included in the national innovation strategy. Unfortunately, social innovation was never clearly articulated and was only vaguely considered to relate to innovations that produced or improved social or welfare benefits. This was qualified with a need for a primary focus on the vulnerable sectors of society, particularly the poor and unemployed. Only the first and the last of the six goals indicated in the White Paper made any mention of social innovation, but failed to define this clearly. Goal One emphasised the need to 'establish an efficient, well-coordinated and integrated system of technological and social innovation' while Goal Six acknowledged a need for improved 'support to all types of innovation fundamental to sustainable economic growth, employment creation, equity through redress and social development'1. Despite the lack of clear articulation of social innovation, the impression conveyed is that social innovation and development are intertwined in some way.

Succeeding policy documents, such as the Innovation towards a Knowledge-based Economy: Ten-year Plan for South Africa 2008-2018, ${ }^{5}$ generally underplayed the idea of social innovation in terms of improved social or welfare benefits in favour of highly technical innovations in line with the Global Grand Challenges, through which any benefits to the poor would occur slowly and indirectly at best. As part of the Human and Social Dynamics Global Grand Challenge, the Department of Science and Technology (DST) recognised the importance of human behaviour in relation to science and technology and proposed areas of multidisciplinary research to better understand such behaviour as a means of using and informing technological innovations and contributing to greater global understanding of human behaviour. It is proposed that the reduction of persistent and chronic poverty in the country will transpire through technological intervention in the provision of better and affordable services, such as health, energy, water and sanitation. Information and communication technologies (ICTs) are seen as crucial for information dissemination and education. However, these ideas are not clearly linked to the development of the poor and marginalised and aim instead at macro or national contributions to specific sectors such as agriculture, space technology, energy and the green economy, and security. This 10-year plan is partly a quick reaction to some of the key criticisms of the 2007 Organisation for Economic Cooperation and Development (OECD) Review of the Innovation Policy of South Africa ${ }^{6}$ and focuses on developing high-level innovation skills in ways that could increase business and research collaboration with OECD countries. The OECD Review noted that 'trickledown' benefits are insufficient to immediately address unemployment and poverty. The reviewers highlighted the importance for improved prioritising of the NSI's contribution to technology and innovation for poverty reduction strategies and improved coordination in terms of resource provision, development and implementation. However, there is no indication in these two documents of the acknowledgement or relevance of less technologically centred innovations such as social organisation and innovative networks that mitigate risk and increase broader participation in society.

Acknowledging the absence of clarity about social innovation and the poor in previous strategies and policy instruments, the 2012 Ministerial Review specifically aimed to illustrate what the idea of social innovation could encompass. ${ }^{2}$ Firstly, the Review Committee equated social innovation with innovation for development (a term itself shrouded in multiple understandings, meanings and practices ${ }^{7}$ ) and stated that social innovation should address priorities arising from unemployment and poverty. For the Committee, this means that social innovation must have social purposes and involve the full range of societal actors, including the public sector, private sector, civil society and the poor. In some way it must be inclusive. However, this focus appears to be strongly related to national development priorities and fails to emphasise the importance of social innovation to local development. ${ }^{8,9}$ Secondly, following observations by rural researchers, ${ }^{10}$ the Review Committee also acknowledged that development for the poor should consider not only the poor as consumers of innovation, but also their immense potential for creative and active agency, ${ }^{2}$ while noting that structural conditions limit their ability to exercise their agency to the fullest. The recognition of the poor as both innovators and consumers of innovations is in itself an important shift away from the narrow view that innovations benefit the poor by means of technological trickle-down effects.

Rather than adopting a broad definition of social innovation, following Petersen ${ }^{11}$, the Review Committee considered the primary focus of social innovation in the South African context to be 'on any appropriate technologies or interventions that can address the challenges of poor communities'2. Of course such challenges faced by poor communities and the possible solutions to these are not simply social but include economic, historical, political and spatial considerations. Although not clearly stated, the adoption of Petersen's perspective suggests that the Committee is in fact more concerned with promoting innovations that are inclusive and have a developmental focus, rather than simply focusing on innovations that have welfare and social benefits. In other words, the Committee seems to be promoting innovations for development, which include the poor as actors and beneficiaries, and involve technical and social innovations with poverty mitigating economic and social outcomes. The remainder of the Review Committee's discussion on social innovation concentrates on listing current and potential flagship projects, strategies and organisations across civil society, the private and the public sectors who could participate in such projects. ${ }^{2}$ Perhaps the most salient features of the Review Committee's discussion is the acknowledgement that the poor are themselves creative and innovative actors and agents in their livelihood and social improvement strategies, but that these activities are often constrained. Unfortunately, ways to overcome fundamental constraints, such as access to resources as a result of prevailing structural conditions within the NSI and society, are not addressed by the Review Committee, possibly because there is limited awareness of the multiple constraints, and especially how these are manifested amongst marginal groups and actors. Also, the Committee seems to confuse social innovation with processes and outcomes that are perhaps better-termed pro-poor innovation given that the focus is not simply on welfare and well-being but more on the role technological products can play with regard to creating economic and social improvements in the lives of the poor and marginalised. This perspective is only one perspective on social innovation.

\section{What do we understand innovation to be?}

Increased interest in and research about innovation has acknowledged the importance of innovation in service and low-technology manufacturing industries, i.e. those outside the mainstream research and development intensive industries, such as high-technology manufacturing.,12-14 Such acknowledgement has led to broadening the definition of innovation to one that moves beyond traditional industries and the traditional approach of 
concentrating on technological product and process innovation. The result is the consideration of social arrangements or organisational structures and social outcomes or products that are equally and fundamentally important for an innovative economy and society as a whole.

According to the third edition of the OSLO Manua/12 and a review of innovation by Gault ${ }^{13}$, the contemporary understanding of innovation is that it involves both processes and the outputs of these processes. The innovation processes are generally accepted to consist of four activities: adoption (the use of innovations), adaption (the improvement of innovations), diffusion (the sharing or transfer of innovations) and invention (the creation of new innovations). ${ }^{12}$ These activities need not be linear although they can be. The outputs of the innovation processes are now generally agreed to include four main types: product (goods and services) innovations, process innovations, marketing strategies and organisational arrangements. ${ }^{12,13}$ In order to be considered an innovation, the product, process, marketing strategy or organisational arrangement must at least be novel to the user, and must be valorised or wanted. ${ }^{13}$ Novelty or newness need not extend beyond the firsttime user to society ${ }^{15}$, while traditionally, value has been couched in commercial terms in the sense that the innovation exclusively improves profits or improves processes that in turn improve profits. Value can also be simply the improvement of knowledge, such as in the case of research undertaken by different disciplines for immediately contributing to the body of knowledge, improving methods to do so, or having the expectation of contributing to social and economic needs over the long term. It is probably only since the turn of this century that social value (such as improving well-being and welfare) has been acknowledged as a means to valorise innovation. ${ }^{16}$ Very simply, value implies usefulness to the user - the more useful, the greater the value.

Despite the multiple and contrasting ideas about innovation and how to achieve greater impacts from innovation, some neoliberal economists still argue that the benefits of innovation ultimately trickle-down indirectly to the most needy and that therein lies the social and economic value of all types of innovations, irrespective of purpose. For example, innovative firms can employ a small number of extra people to develop products that generate revenue as well as improve other aspects of society, such as lowering the carbon footprint or providing improved medicines, transportation systems or communication systems - activities that can be considered socially innovative. However, the increasing awareness of the need for more direct benefits for the large number of marginalised and vulnerable members of society, and their role as innovators, has resulted in the call for more direct socially focused innovations.

\section{Contemporary understandings of social innovation}

A review of recent international literature on social innovation ${ }^{17}$ suggests that although the term is contested, there are three primary definitions of social innovation used globally. However, each definition has its own dissenters who propose further qualifications to emphasise what should be categorised as a social innovation.

Firstly, social innovations are largely considered to be products (goods and services) with human welfare or social benefit outcomes, including better health, education, improved water access, cost-efficient energy devices and products that improve communication and transportation. The output is socially oriented and for our purposes, we term this the social product definition. However, some emphasise that to be considered as social innovations, such products must be social and public goods. ${ }^{18}$ In this regard, innovations in the private sector, such as vaccines, are excluded, as they are not public goods although they have social benefit. Others argue that Internet search engines developed in the private sector and owned by private enterprises are social innovations because the value to society outweighs profits to private sector. ${ }^{19}$

The second definition of social innovation considers the organisation or arrangement of people and things within enterprises or social settings (informal or formal organisations and arrangements). ${ }^{17}$ There is a social process. Examples include trade unions, bargaining councils, worker forums, job sharing, stokvels, neighbourhood watch committees, rural neighbourhood or kin-based work parties, grazing and land-management committees, and even various product distribution and sales methods. We term this the social collaboration definition.

The third definition of social innovation is a combination of the first two. Social innovations are those new products, services, models and practices that concurrently meet social requirements and involve new social collaborations. To be considered social innovations under this definition, innovations must have both a social means and end, in that potential recipients must decide what has to be done and do it (but can draw on external resources and advice). We term this the social means and ends definition. Furthermore, such innovations must achieve broad systemic transformation, ${ }^{14}$ in the sense that the prevailing structure of the innovation system (global, national, regional and local) is altered and improved. However, like the first definition, innovations occurring in commercial enterprises are excluded. A social process is used to bring about a social outcome and it is the presence of new social processes that catalyse systemic change.

However, is it correct, or even relevant and helpful, to distinguish innovations with social purposes and means from other innovations, purely based on the processes involved and the intended outcomes, benefits and beneficiaries? Clearly, given the numerous examples, the social collaboration definition focuses on the social arrangement of people irrespective of their location in formal or informal commercial or social enterprises and the formal or informal nature of the social arrangement. Consequently, if we are to talk about social innovation, it seems rather naìve to ignore social innovations occurring in commercially oriented enterprises ${ }^{20}$, irrespective of the scale of such enterprises ${ }^{21}$. The sustained presence of social arrangements suggests that they must have benefits for all actors involved. Evidence from the RIAT pilot study suggests that perhaps we should not be too quick to narrow the parameters of social innovation.

\section{Evidence from innovating enterprises in South Africa}

Using a purposive snowball sampling technique as part of the RIAT pilot study in four South African rural district municipalities (RDMs), we formally interviewed representatives from 482 formal and informal enterprises using a structured questionnaire which comprised qualitative and quantitative questions. The methodology was approved by the Research Ethics Committee of the Human Sciences Research Council (protocol no. REC5/24/04/13). Identified enterprises were screened by interviewees and had to have been engaged in at least one of the four innovation activities during 2011 or 2012. Enterprises from the primary sector (agriculture, forestry, mining and minerals) accounted for $30 \%$ of the sample. Those from the secondary sector (manufacturing and energy) accounted for $16 \%$ of the sample and those from the tertiary sector (providers of tertiary services including ICT, health, education, finance and community services) accounted for $54 \%$. While not conclusive, this evidence suggests that the tertiary sector enterprises are important innovation actors in the sampled RDMs. Although the public enterprises had the largest share of actors $(71 \%)$ in the tertiary sector, almost half of the private (49\%) and non- profit (48\%) enterprises were also involved in this sector. This evidence suggests that social innovation, at least in terms of providing basic services and welfare benefits, is undertaken by a significant share of enterprises based in the RDMs.

\section{Main innovation activities}

Most respondents perceive that innovation is something new but should involve technology and improve the revenue of the user. Such ideas reaffirm traditional perceptions of innovation being linked to technology and business. Broad ideas of innovation activities were not initially acknowledged by respondents but when directly asked about innovation activities, we see in Table 1 that of those respondents involved in innovation activities during 2012, many were actively engaged in activities such as adoption (53\%), adaption (29\%) and diffusion (24\%) of existing innovations. Only a handful of rural-based enterprises were engaged in the invention of new innovations (7\%). Public enterprises 
and non-profit enterprises, many of which are involved in the community services sector, tended to be more active with regard to adopting and diffusing innovations. On the other hand, the private sector enterprises, which are mainly profit driven, tended to be more involved in adoption and subsequent adaption.

\section{Awareness of science, technology and innovation policy and support}

Only $28 \%$ of the enterprises acknowledged an awareness and understanding of South Africa's STI policies. Often this knowledge was based on specific sector-related polices, such as those emanating from specific line departments other than DST, rather than the national strategy as a whole. Almost two-thirds (63\%) of the enterprises investigated were aware of government support for innovation activities in the private sector. However, the most aware were the non-profit enterprises (73\%). Slightly more than a third (38\%) of all enterprises had applied for government support, with the private sector enterprises having the lowest share of applicants (22\%) and the non-profit enterprises having the highest share, at $59 \%$.

\section{Social innovation awareness}

The awareness of social innovation amongst these rural-based enterprises was even lower than their understanding of STI policies. In Table 2 we see that only $22 \%$ of the respondent rural enterprises were aware of the concept of social innovation. The greatest share of awareness (36\%) was found among public enterprises and less than $20 \%$ of both private and non-profit organisations had any awareness of the concept. These figures are fairly dismal, but reinforce the fact that social innovation has not been actively articulated or disseminated since its initial inclusion into South African innovation policy in 1996.

\section{Reasons for innovating}

Table 3 illustrates the responses of the enterprises with regard to their main reasons for innovating. Commercial purposes include increasing profits of enterprise and market share, meeting subsistence and survival needs, and innovation to improve the body of knowledge (activities undertaken by research institutes). Social improvement includes products, services and arrangements that directly improve society and the poorer members in particular, and is involved in research with this focus. While $2 \%$ of the respondents were uncertain why their enterprises were innovating, more than half $(56 \%)$ reported that this was for commercial purposes. The majority of public sector enterprises $(76 \%)$ were innovating for social improvement purposes and the majority of private sector enterprises $(86 \%)$ were innovating for commercial purposes. Interestingly, the gap between these purposes is not so great for the non-profit enterprises although the greatest share (56\%) focused on social improvement. This gap might be because of the high level of competition for resources to provide services in this sector and the resultant need to supplement grant income in creative ways - ways that require innovations that increase income. In addition, it might reflect the fact that some nonprofit enterprises, especially those linked to government projects and

Table 1: $\quad$ Share (\%) of enterprises engaged in innovation activities by enterprise type during 2012

\begin{tabular}{|c|c|c|c|c|c|c|}
\hline \multicolumn{2}{|c|}{ Innovation activity } & \multirow{2}{*}{$\begin{array}{c}\begin{array}{c}\text { Valid } \\
\text { observations }^{\dagger}\end{array} \\
34\end{array}$} & \multirow{2}{*}{$\begin{array}{c}\begin{array}{c}\text { Share }(\%) \text { of public } \\
\text { enterprises } \\
(n=96)\end{array} \\
7\end{array}$} & \multirow{2}{*}{$\begin{array}{c}\begin{array}{c}\text { Share }(\%) \text { of private } \\
\text { enterprises } \\
(n=201)\end{array} \\
7\end{array}$} & \multirow{2}{*}{$\begin{array}{c}\begin{array}{c}\text { Share }(\%) \text { of non-profit } \\
\text { enterprises } \\
(n=179)\end{array} \\
\end{array}$} & \multirow{2}{*}{\begin{tabular}{|c}
$\begin{array}{c}\text { Share (\%) of all enterprises } \\
\text { innovating during } 2012 \\
(n=476)\end{array}$ \\
\end{tabular}} \\
\hline & Yes & & & & & \\
\hline & No & 441 & 93 & 93 & 93 & 93 \\
\hline \multirow{2}{*}{ Adopt } & Yes & 252 & 45 & 58 & 52 & 53 \\
\hline & No & 224 & 55 & 42 & 48 & 47 \\
\hline \multirow{2}{*}{ Adapt } & Yes & 139 & 20 & 37 & 26 & 29 \\
\hline & No & 338 & 80 & 63 & 74 & 71 \\
\hline \multirow{2}{*}{ Diffuse } & Yes & 116 & 29 & 19 & 28 & 24 \\
\hline & No & 359 & 71 & 81 & 72 & 76 \\
\hline
\end{tabular}

'Valid observations refers to the number of non-missing values

Table 2: $\quad$ Share (\%) of enterprises aware of the term social innovation by enterprise type

\begin{tabular}{c|c|c|c|c}
\hline \hline $\begin{array}{c}\text { Aware of social } \\
\text { innovation }\end{array}$ & $\begin{array}{c}\text { Share (\%) of public enterprises } \\
(\boldsymbol{n}=\mathbf{9 7})\end{array}$ & $\begin{array}{c}\text { Share (\%) of private enterprises } \\
(\boldsymbol{n}=\mathbf{2 0 2})\end{array}$ & $\begin{array}{c}\text { Share (\%) of non-profit enterprises } \\
(\boldsymbol{n}=\mathbf{1 7 9 )}\end{array}$ & $\begin{array}{c}\text { Share (\%) of all enterprises } \\
(\boldsymbol{n}=\mathbf{4 7 8})\end{array}$ \\
\hline \hline Yes & 37 & 19 & 17 \\
\hline No & 63 & 81 & 83 \\
\hline
\end{tabular}

Table 3: $\quad$ Share (\%) of enterprises engaging in innovation activities for commercial or social welfare purposes by enterprise type

\begin{tabular}{l|c|c|c|c}
\hline \hline $\begin{array}{c}\text { Main purpose of innovation } \\
\text { activities }\end{array}$ & $\begin{array}{c}\text { Share (\%) of public enterprises } \\
(\boldsymbol{n = 9 8 )}\end{array}$ & $\begin{array}{c}\text { Share (\%) of private enterprises } \\
(\boldsymbol{n}=\mathbf{2 0 2})\end{array}$ & $\begin{array}{c}\text { Share (\%) of non-profit enterprises } \\
(\boldsymbol{n}=\mathbf{1 8 2})\end{array}$ & $\begin{array}{c}\text { Share (\%) of all enterprises } \\
(\boldsymbol{n}=\mathbf{4 8 2})\end{array}$ \\
\hline \hline Commercial purposes & 22 & 86 & 41 \\
\hline Social improvement purposes & 76 & 13 & 57 \\
\hline Uncertain & 2 & 1 & 2 \\
\hline
\end{tabular}


community groups, aim to generate an income for members as part of poverty-reduction strategies.

\section{Local understandings of social innovation}

Local understandings of social innovation are often contested and do not always coincide with those used by policymakers and researchers. Responses to in-depth qualitative questions indicate that a fair number of respondents representing rural enterprises believe they are involved in innovation activities that have social or welfare purposes, in the sense that there is a very direct link to providing or improving social services, addressing community needs and helping others in their immediate proximity. This belief was particularly so for respondents from public and non-profit enterprises who mentioned targeting the poor, less fortunate and marginalised. However, some of the respondents representing private enterprises perceived their profit-making products, processes and strategies as being social innovations in that these ultimately have a social benefit, even if only indirectly.

Some farmers indicated that the use of improved seeds, plant material and inputs that improved food quality and availability improved national food security, even if the use of these technological innovations ultimately increased food prices. Similarly, some credit providers argued that the use of innovative microfinance arrangements that ensure the repayments of loans, rather than their affordability, were also social innovations in that by ensuring repayment they were ultimately able to provide credit to more people. Others suggested that creating a few jobs for other people, while significantly increasing the income of the innovating entrepreneur, were also social innovations because these activities enabled others to earn an income, thereby reducing unemployment, even if this income was far below that of the entrepreneur.

Undoubtedly, the above are innovations - but are they social innovations? While the social impacts of these examples are very indirect and at best have a limited and gradual effect on the well-being of the less fortunate, they also have potentially far-reaching negative effects. These negative effects include raising the price of foodstuffs and decreasing farm employment opportunities, increasing the debt of those whom can ill afford it and increasing the number of low-paid jobs. Although there are some elements of social benefit, the primary aim of such 'social innovations' still appears to be the immediate improvement of enterprise turnover and revenue, and as a result there is no tangible benefit for the poor.

In these four RDMs, the perceptions of innovators about the purpose and beneficiaries of social innovation are blurred, although there is an indication that the poor or less fortunate should benefit more directly - a view mainly expressed by public and non-profit sector organisations. Given this context, to simply introduce a new and rather broad concept, such as social innovation, into South Africa's innovation system is likely to create more problems than it solves. Already there are numerous terms used in the development discourse that are simply buzzwords adopted by actors and agencies to promote and generate support for their ideals. These terms include empowerment, pro-poor, participation and poverty reduction. Unfortunately, they have multiple meanings and can be used and translated by actors and agencies as they desire and for very different purposes. ${ }^{22}$ The concept of social innovation, with its multiple foci and qualifications faces similar challenges. ${ }^{23}$

\section{Towards an actor-oriented sociology of innovation}

At present, South African innovation policy tends to lump social innovation with pro-poor development, focusing on products that better serve the poor, and closely linking the definition of social innovation to a social product. We see from the international literature that this definition is insufficient. ${ }^{20,21,23}$ It ignores innovation as social collaboration - i.e. innovative social processes. It also excludes the broader product and means definition, with its structural altering intentions. However, our research indicates that clear definitions of social innovation are not possible, as they do not exist neatly in South African rural areas. Furthermore, innovation of a social nature is not simply confined to producing social goods and services exclusively for the poor. Alarmingly, while innovation occurs in rural areas, very little seems to be immediately linked to or acknowledged by the broader system of innovation unless it is highly formalised. This is especially the case for non-traditional innovations and those undertaken by the poor in marginal areas. These factors make it necessary to consider the prevalence of structural challenges that possibly permeate the NSI and mediate against increased innovation in rural areas. A simple focus on social innovation in any of the three definitions is inadequate. The focus must be broader in our view, so that it includes both social and economic purposes of innovation, as well as technological and social processes and products. Currently any 'labelling' of something as a social innovation runs the risk of confining it too simply to the social product definition.

Similar to Neumeier ${ }^{23}$, we propose that a first step out of the existing policy and real-world impasse would be to adopt a sociological actororiented approach to understanding the social life of innovation generally, irrespective of the social, technical or economic outputs, purposes and class of beneficiaries. An actor-oriented sociological approach to innovation would enable a better understanding of the social, cultural, political, economic, historical and structural factors that influence innovation activities and the capability to innovate. The actor-oriented works of Latour ${ }^{24}$ on the sociology of science, Long ${ }^{25}$ on the sociology of rural development and Mosse and Lewis ${ }^{26}$ on local and international development, provide relevant insights into the 'social life' or 'real world' of science and development projects. By focusing on the actors we are able to understand what is taking place and why, along with the relationships between the various actors involved at different levels of the global, national, regional and local innovation system and innovation activity. ${ }^{24} \mathrm{~A}$ similar sociological perspective of innovation would show that actors are often in conflict with one another over resources and have different perceptions on needs and contrasting world views, despite outward appearances of collaboration. ${ }^{23,25}$ Inconsistencies in processes and support are revealed when often there first appear to be none, deepening our understanding of the dynamic and changing relationships between people and people, and people and things. ${ }^{24}$

Any discussion about the social qualities of innovation must also look at the social process or life of innovation. This is a necessary first step to understanding innovation processes, challenges and contributions to society. To ignore this would be to overlook a crucial element of innovation, i.e., it is not simply a technocratic process, but one that is governed by political, social, economic and historical factors. Most innovations have some degree of social benefit, either for immediate users or for others who are indirect beneficiaries. This characteristic enables people to suggest that almost all innovations have a social benefit. As noted in the current study, some innovations may have negative long-term effects that are not immediately acknowledged or realised. It is important to understand why some innovations are acknowledged, encouraged and supported, rewarded and diffused while others are simply ignored or unrecognised as innovations. This necessitates a deep understanding of the actors involved at different tiers of the innovation system.

The RIAT pilot study shows that, in rural areas, awareness of STI policy by innovating enterprises is low, especially innovations with social objectives, and that while awareness of the availability of support is relatively high, the support seeking activities are low. The study also suggests that a significant share of innovation takes place in the tertiary or service sector. However, innovation in rural areas is generally equated with agricultural innovation and less so with mining (the two key actors in the primary sector). Why does innovation in the tertiary sector remain unacknowledged? Invention is low in rural areas but there is no clear explanation for this unless it has to do with how resources are currently distributed within the NSI. Innovations with social foci are not as prevalent as those with a commercial focus but comprising $42 \%$ of the sample they are significant and deserve to be acknowledged. Even if the focus of such innovations is not in line with the multiple current definitions, their contribution to society needs to be a focus of policy research, and better understood. 


\section{Conclusions}

The evidence from the RIAT pilot study used in this paper shows that there are gaps in policy implementation since the introduction of the White Paper on Science and Technology in 1996, while the review of recent policy papers shows that these papers do not sufficiently address the gaps. As Neumeier ${ }^{23}$ points out, there is a need to go beyond the simple assessment of rural innovation projects and activities to explicitly investigate and interrogate factors that promote or constrain innovation in the area between top-down and bottom-up rural development approaches. A sociological approach presents a refreshing research focus to understand the social face of innovation activities and outcomes generally, without the obscurity created by multiple definitions of social innovation. It is an approach that is more encompassing than those currently suggested in policy documents and is drawn from evidence of innovating enterprises in marginal rural district municipalities.

An actor-oriented sociological approach to innovation provides a point of departure for a deeper understanding of capabilities and access to resources, decision-making and the reasons for these. Perhaps more importantly, when structural transformation is necessary, as in South Africa, this approach could highlight the existing power relations within the NSI, across the broader STI and development policy-making frameworks, and the effects of these relationships at different levels of these frameworks. Inevitably, this approach will deepen our awareness of who benefits (and who does not) from innovation policies and interventions and why and how this occurs. It would also identify more clearly the social and economic factors that underpin the innovation process, purposes and outcomes more clearly and would put these in a context in which it would be easier to understand the developmental impacts of innovation and innovations broadly without being confined simply to process and outcomes.

In order to determine the broader developmental contributions of innovation, the adoption of an actor-oriented sociology of innovation appears to have much to offer to our understanding of innovation actors, agency, processes and their outcomes along with the nature of the innovation system. This can be considered a necessary step to deepening our understanding of the national, sub-national, regional and sectoral innovation systems in South Africa and lead towards identifying the structural and systemic changes, beyond repetitive quantitative monitoring and the simple creation of new entities and new foci, as proposed in the 2012 Ministerial Review document. Innovation, including social innovation in its broadest sense, cannot be truly understood without a sociological perspective.

\section{Acknowledgements}

In this article, we draw on evidence obtained during the Rural Innovation Assessment Toolbox (RIAT) Pilot study undertaken by Economic Performance and Development (EPD) researchers of the Human Sciences Research Council during 2012 and 2013. We acknowledge the financial support of the Department of Science and Technology as well as the collegial inputs and discussions with fellow researchers Brandon Bodenstein, Hlokoma Mangqalaza, Alex Mhula and Makale Ngwenya. The comments and suggestions of the Associate Editor, Pearl Sithole, and two unknown reviewers are deeply appreciated. The views expressed are those of the authors and do not necessarily reflect those of any other party.

\section{Authors' contributions}

T.G.B.H. was the lead author who conceptualised the study and conducted the literature review and qualitative analyses. K.H.R. and P.T.J. conducted the quantitative analysis and contributed to rewriting various drafts. B.A.L. assisted in the qualitative and thematic analysis and the rewriting of various drafts.

\section{References}

1. DACST (Department of Arts, Culture, Science and Technology). White paper on science \& technology: Preparing for the 21st century. Pretoria: Department of Arts, Culture, Science and Technology; 1996
2. DST (Department of Science and Technology). Department of Science and Technology Ministerial Review Committee on the science, technology and innovation landscape in South Africa: Final report 2012 March. Pretoria: Department of Science and Technology; 2012.

3. Marcelle G. Editorial. Int J Technol Learn Innov Dev. 2012;5(1/2):1-11.

4. Gupta AK. Innovations for the poor by the poor. Int J Technol Learn Innov Dev. 2012;5(1/2):28-39. http://dx.doi.org/10.1504/IJTLID.2012.044875

5. DST (Department of Science and Technology). Innovation towards a knowledgebased economy: Ten-year plan for South Africa (2008-2018). Pretoria: Department of Science and Technology; 2007.

6. Organisation for Economic Cooperation and Development (OECD). OECD reviews of innovation policy: South Africa. Brussels: OECD; 2007.

7. Willis K. Theories and practices of development. New York: Routledge; 2009.

8. Committee for Scientific and Technological Policy, Organisation for Economic Cooperation and Development (OECD). Fostering innovation to address social challenges. Paris: OECD; 2011.

9. Gerometta J, Haussermann H, Longo G. Social innovation and civil society in urban governance: Strategies for an inclusive city. Urban Stud. 2005;42(11):20072021. http://dx.doi.org/10.1080/00420980500279851

10. Cousins B. Rural innovation systems. Paper prepared for the Ministerial Review Committee on the science, technology and innovation landscape in South Africa. Pretoria: DST; 2011 [unpublished report].

11. Petersen F. 2011. Specialist report on social innovation and sustainability. Paper prepared for the Ministerial Review Committee on the science, technology and innovation landscape in South Africa. Pretoria: DST; 2011 [unpublished report].

12. Organisation for Economic Cooperation and Development/Statistical Office of the European Communities (OECD/Eurostat). The measurement of scientific and technological activities - Oslo manual: Guidelines for collecting and interpreting innovation data. 3rd ed. Paris: OECD/Eurostat; 2005

13. Gault F. Innovation strategies for a global economy: Development, implementation, measurement and management. Ottawa: International Development Research Centre; 2010.

14. Young Foundation / Social Innovation eXchange (YF/SIX). Study on social innovation. A paper prepared by the Social Innovation Exchange (SIX) and the Young Foundation for the Bureau of European Policy Advisors [document on the Internet]. c2010 [cited 2012 Dec 06]. Available from: http://youngfoundation.org/ wp-content/uploads/2012/10/Study-on-Social-Innovation-for-the-Bureau-ofEuropean-Policy-Advisors-March-2010.pdf

15. Rogers EM. Diffusion of innovations. New York: Free Press; 1995.

16. Moulaert F, Martinelli F, Swyngedouw E, Gonzalez S. Towards alternative model(s) of local innovation. Urban Stud. 2005:42(11):1969-1990. http://dx.doi. org/10.1080/00420980500279893

17. Hart T, Jacobs $P$, Mangqalaza $H$. Key concepts in innovation studies - Towards working definitions. RIAT Concept Paper Series - Concept Paper 2. Pretoria: Human Sciences Research Council; 2012.

18. Harris M, Albury D. The innovation imperative. The LAB Discussion Paper, 2009 March. London: NESTA; 2009

19. Phillis JA, Deiglmeier K, Miller DT. 2008. Rediscovering social innovation. Stanford Soc Innov Rev. 2008;Fall:33-43.

20. Datta PB. Exploring the evolution of a social innovation: A case study from India. Int J Technol Manag Sustain Dev 2011;10(1):55-75. http://dx.doi.org/10.1386/ tmsd.10.1.55 1

21. Godoi-deSousa E, Valadao Junior VM. Social enterprises in Brazil: Socially produced knowledge versus social innovation. J Technol Manag Innov 2013:8:166-176.

22. Cornwall A, Brock C. What do buzzwords do for development policy? A critical look at 'participation', 'empowerment' and 'poverty reduction'. Third World $Q$. 2005;26(7):1043-1060. http://dx.doi.org/10.1080/01436590500235603

23. Neumeier S. Why do social innovations in rural development matter and should they be considered more seriously in rural development research? - Proposal for a stronger focus on social innovations in rural development research. Sociol Ruralis. 2011;52(1):48-69. http://dx.doi.org/10.1111/j.1467-9523.2011.00553.x

24. Latour B. Aramis or the love of technology [translated by Catherine Porter]. Cambridge, MA: Harvard University Press; 1996.

25. Long N. Development sociology: Actor perspectives. London: Routledge; 2001. http://dx.doi.org/10.4324/9780203398531

26. Mosse D, Lewis D. Theoretical approaches to brokerage and translation in development. In: Lewis D, Mosse D, editors. Development brokers and translators: The ethnography of aid and agencies. Bloomfield, CT: Kumarian; 2006. p. 1-26. 